\title{
An ecological analysis of secondary school students' drug use in Hong Kong: A case-control study
}

\author{
Samson Tse ${ }^{1}$, Shim in $\mathrm{Zhu}^{1}$, Chong Ho $\mathrm{Yu}^{2}$, Paul W ong ${ }^{1}$ and Sandra Tsang ${ }^{1}$
}

\begin{abstract}
Background: Youth drug use is a significant at-risk youth behaviour and remains as one of the top priorities for mental health services, researchers and policy planners. The ecological characteristics of secondary school students' behaviour in Hong Kong are understudied.

Aim: To examine individual, familial, social and environmental correlates of drug use among secondary students in Hong Kong.

Method: Data were extracted from a school survey with 3078 students. Among the 3078 students, 86 students reported to have used drugs in the past 6 months. A total of 86 age- and gender-matched controls with no drug-use behaviour in the past 6 months were randomly selected from the remaining students. Multiple logistic analysis was used to examine differential correlates between those who used and did not use substance in the past 6 months.

Result: Positive school experience and perspective to school and parental support are protective factors of drug use. Lower self-esteem, lower self-efficacy against using drugs and higher level of permissive attitude towards drugs were associated with drug use. Students who were low in self-esteem and rather impulsive tend to use drugs.

Conclusion: To prevent students from drug use, efforts in individual, family, school and community-levels should be addressed.
\end{abstract}

\section{Keywords}

Mental health, substance use , ecological approach

\section{Introduction}

The incident cases of drug use among young people aged below 21 years surged more than 50\% between 2004 (2186 cases) and 2008 (3474 cases) and then gradually decreased down to 1182 cases in 2013 in Hong Kong (Narcotics Division of the Security Bureau, Hong Kong Special Administrative Region, 2014). The percentage of students ever having used drugs in lifetime in secondary schools (usually at or under 18 years old) rose from 3.3\% in $2004 / 2005$ to $4.3 \%$ in $2008 / 2009$ and that the number of youth using drugs within the last 30 days had almost doubled, from $0.8 \%$ to $1.5 \%$ (Narcotics Division of the Security Bureau, Hong Kong Special Administrative Region, 2010). According to the Monitoring the Future survey by the National Institute on Drug Abuse (2013) in the United States, drug use among teenagers remains high; for instance, $18.0 \%$ of 9th graders and $22.7 \%$ of 10th graders used marijuana in the past month. Moreover, the attitude towards drug use among students is worrisome. According to a large-scale survey of over 2700 senior primary school students (US equivalent would be Grades 5 and 6 in elementary schools) in 39 primary schools in Hong Kong, around 30\% did not see drug use as having a negative effect on their image among their peers, while around $12 \%$ did not think that the use of Ketamine, Ecstasy and cough medicine would damage their future. Over $20 \%$ of the participants thought that using Ketamine and Ecstasy would not easily lead to addiction, and over $30 \%$ of the sample said they lacked confidence in their ability to control themselves and resist the temptation to take drugs (Barnabas Charitable Service Association Limited, 2009). Youth drug use and addiction remain top priorities for health and human services, researchers and policy planners both locally and internationally (Barlow, 2010; Gossop, 2007).

Numerous correlates and predictors of youth drug use have been identified in previous studies. However, understanding of this youth issue using an ecological

\footnotetext{
${ }^{1}$ Department of Social Work and Social Administration, The University of Hong Kong, Hong Kong

${ }^{2}$ Department of Psychology, Azusa Pacific University, Azusa, CA, USA
}

Corresponding author:

Samson Tse, Department of Social Work and Social Administration, Faculty of Social Sciences, The University of Hong Kong, Jockey Club Tower, The Centennial Campus, Pokfulam Road, Hong Kong. Email:samsont@hku.hk 
perspective is less common. Using an ecological perspective to frame the issue allows a non-pathology and non-deficits-oriented theoretical basis which emphasizes the interaction of elements within different systems that impacts on drug use (Stormshak \& Dishion, 2009). The Ecological Systems Theory (EST) (Bronfenbrenner, 1986; Kuo, Lin, \& Li, 2012) proposes that individuals are affected by five systems that interact and mutually affect each other and the individual: (1) Microsystem - the person's immediate environment (e.g. family, peer group, school); (2) Mesosystem - interrelations between different microsystems (e.g. the interactions between family and school system); (3) Exosystem - external settings that do not involve the person as an active participant but still affect the person or are affected by the person (e.g. studyrelated stress affects a high school student's mood, and thus he uses drugs to cope with the stress); (4) Macrosystem - wider cultural and underlying ideological context (e.g. filial piety within Chinese communities); and (5) Chronosystem - the effect of time or the dimension of life span (e.g. physiological change for a young person). EST is particularly helpful in developing preventive efforts that address each of the relevant systems or layers and the interplay between them (Randall \& Cunningham, 2003). For details on the application of EST among young people affected by drug use and/or abuse, consult a recent review by Hong, Huang, Sabri, and Kim (2011)

Two recent studies have adopted a similar 'ecological perspective' in studying drug use among young people. Knyazev (2010) surveyed 3476 Russian college and university students to investigate the effect of social environment (in particular peer, parent and boyfriend/girlfriend relationships) and behavioural activation personality factors (e.g. sensation seeking, psychoticism) on young people's drug-use behaviours. It was found that behavioural activation acted as a reliable predictor of young people's drug-use status. The extent to which the social environment moderated the strength of the association between drug use and personality predisposition depended on the young person's gender (e.g. the effect of personality predisposition was more prominent in females) (Knyazev, 2010). Given that, compared with Knyazev's work, the present project is concerned with a relatively younger age group and included young people's studies and secondary school experience as part of their social environment. Another closely relevant study was conducted in the United States. This study performed a secondary analysis of a large archival data set from the National Longitudinal Study of Adolescent Health, measuring health at baseline, first and sixth/seventh year (Wheeler, 2010). It was concluded that among young girls, but not boys, high academic performance and bolstering self-esteem were protective factors against risky behaviours such as drug use and early sexual intercourse.

This study also adopted an ecological perspective and aimed to examine student drug-use behaviour using a case-control methodology. The aims of the present school-based survey were twofold: (1) to investigate differences in ecological characteristics between adolescents who self-reported using drugs and a matched control group (by age and gender) and (2) to identify which characteristics are linked to drug-use status.

\section{Method}

\section{Participants}

Eleven of the 15 targeted secondary schools (73.3\%) in one of the 18 districts of Hong Kong agreed to participate in the present survey. All of these secondary Form 1 to $7^{1}$ (US equivalent would be Grades 7 to 12) are part of public system providing free education. Within each participating school, two to three classes were randomly selected from each of five of the seven forms (Forms 1, 2, 3, 4 and 6). Form 5 and Form 7 students were excluded as they have to sit for public examinations in the year. The inclusion criteria were that a student must (1) attend a school in the district, (2) be aged 12-18 years, (3) engage personal and parents'/guardians' consent to participate in the survey, (4) read and write in Chinese, and (5) have sufficient concentration to complete the survey.

A total of 3160 students completed the questionnaire. The research team excluded those responses to the questionnaires where the participants showed dubious completion style (e.g. marked the same score across more than three sections of the questionnaire). In all, 3078 (97.4\%) observations were included in the data set. Students were asked, 'Have you ever used the following illicit drugs in the past six months? If yes, please mark the column next to the name of drug'. Nine illicit drugs were listed (Ecstasy, ketamine, marijuana, heroin, cocaine, ice, organic solvent, codeine and pills such as Blue Gremlin and Five). In the present analysis, 86 participants who self-reported drug use of any kind in the past 6 months (2.8\%) and a control group of 86 age- and gender-matched participants who self-reported that they had not used drugs were compared. The control group participants were randomly selected from the wider sample, excluding the 86 participants with drug use ( $n=2992)$ and matching with the gender and age of the drug-using group. The matching was obtained by first preparing a pool of non-drug-using participants matched by age and gender and then randomly picking every 25th or 30th case on the list depending on the number of participants required and how big the pool was (e.g. 10 boys aged 14 years reported using drugs and there were 320 boys in the same age pool, thus every 30th boy on the 
list was picked to obtain the matched participants). In addition to matching demographic characteristics of the two groups, statistical reasoning was also taken into account. Specifically, if 86 cases were compared against 2992 controls, the two variances are extremely asymmetrical, thus violating the assumptions of most parametric tests.

\section{Instruments}

Demographic characteristics. Demographic information covered the participants' age, gender, educational level, birthplace and level of pocket money received from family (monthly).

Ecological characteristics. Ecological characteristics provided an assessment of the participants' experience at schools, family relationships, peer influences and psychological characteristics. Three out of the 9 items from the Positive Orientation to School Scale (Jessor, Van Den Bos, Vanderryn, Costa, \& Turbin, 1995) were used in the present study. These items measure young people's perception of school and the values they place on academic achievement. The internal consistency (Cronbach's alpha) obtained in the present study was .71 based on 172 youth participants. A Cronbach's alpha around .70 is considered acceptable (Nunnally, 1978). Perceived emotional and instrumental support from the family was measured by 12 items from the Perceived Parental Support Scale (Wills, Vaccaro, \& McNamara, 1992). The alpha achieved was .94. The influence of peers was measured using 4 items from the Extreme Peer Orientation Scale (Fuligni \& Eccles, 1993). This instrument was used to determine whether adolescents place such a high importance on their relationships with their peers that they would sacrifice positive aspects of their lives to maintain these relationships. The alpha coefficient obtained in the present study was .71.

Psychological characteristics covered the participants' self-esteem, attitude towards using drugs, self-efficacy against using drugs and impulsivity and social desirability. Rosenberg Self-Esteem Scale was administered to investigate the participants' global selfesteem. This instrument contains 10 items; it has been adopted in various studies among Chinese youths (Lee \& Lee, 2000; Shek, 1997). The Cronbach's alpha obtained in the present study was .86. An 8-item Self-Efficacy Scale was adapted to determine the participants' intention to refrain from drug use when offered drugs (DeVires, Dijkstra, \& Kuhlman, 1988). The alpha coefficient obtained in the present study was .86. Attitudes towards using drugs were explored through a scale adopted from a youth drug research project in Hong Kong (The Hong Kong Federation of Youth Groups, 2008). The alpha achieved was .69. Seven items focusing on 'non-planning impulsiveness', which represents the two first-order factors, namely, 'self-control' and 'cognitive complexity', were selected from the Barratt Impulsivity Scale (Patton, Stanford, \& Barratt, 1995) to investigate the participants' tendency to plan their behaviour or to act impulsively. The original item 'I plan for job security' as part of the 'non-planning impulsiveness' factor structure was omitted from the present survey as the research team felt that it would not be relevant to the participants in the present survey (average age: 15 years). The alpha achieved was .80 . Social desirability was to examine how much the answer of participants was influenced by their tendency to answer questions in a manner that would be viewed favourably by others. It was assessed by 4 items (e.g. 'never been late', 'never tell a lie') and asked over two consecutive years. The alpha was .86 .

\section{Procedure}

Initially, a small Youths Advisory Group (YAG) of four young people was formed to steer the design and implementation of the project. The research team introduced and promoted the project in meetings attended by school principals or senior management in order to solicit their participation. Teachers in the participating schools gave students the study information sheet and consent form to take home. Upon completing the questionnaire in classroom, each student was asked to put the questionnaire into the envelope provided and return it to the research assistant. The above procedures separating the signed consent form and the completed questionnaire were strongly recommended by the YAG in order to give the participants confidence that the research team had endeavoured to protect their identity. The whole data collection session lasted between 15 and 20 minutes. Ethical approval for the present study was obtained from the Hong Kong University Human Research Ethics Committee for Non-clinical Faculties (24 March 2010).

\section{Satistical analysis}

JMP Pro version 11 (SAS Institute, 2013) was utilized for all of the statistical analyses. Demographic characteristics and the ecological and psychological results were tabulated with descriptive statistics. Either two-sample $t$ tests were used to compare group means or Chi-square $\left(\chi^{2}\right)$ tests to compare proportions. The preceding statistical tests were two-tailed, and a $5 \%$ significance level was maintained throughout the analyses. To 
Table 1. Demographic, ecological and psychological characteristics of 172 participants: Self-reported drug use $(n=86)$ and no drug use $(n=86)$ in the last 6 months.

$\begin{array}{lll}\text { Drug-using group: means } & \text { Control group: means } & \text { Tests of } \\ \text { (standard deviation) or \% } & \text { (standard deviation) or \% } & \begin{array}{l}\text { difference: } \chi^{2} \text { or } t \text { - } \\ \text { test }\end{array}\end{array}$

\begin{tabular}{|c|c|c|c|}
\hline \multicolumn{4}{|l|}{ Demographic characteristics } \\
\hline Mean age & $15.1(2.17)$ & $14.9(1.76)$ & .618 \\
\hline Gender (male) & 58.3 & 49.5 & 1.791 \\
\hline Educational level & & & 1.355 \\
\hline $\mathrm{F} 1$ & 25.6 & 24.7 & \\
\hline F2 & 20.9 & 24.7 & \\
\hline F3 & 20.9 & 15.3 & \\
\hline $\mathrm{F} 4$ & 14.0 & 12.9 & \\
\hline F6 & 18.6 & 22.4 & \\
\hline Ethnicity & & & 3.750 \\
\hline Chinese & 90.7 & 97.6 & \\
\hline Non-Chinese (e.g. Filipino, Japanese) & 9.3 & 2.4 & \\
\hline Born in Hong Kong (yes) & 77.6 & 76.2 & .050 \\
\hline Live with & & & 5.201 \\
\hline Both father and mother & 70.9 & 73.8 & \\
\hline Single parent & 23.3 & 21.4 & \\
\hline Friends only & 5.8 & 4.8 & \\
\hline Pocket money (per month) & & & 5.718 \\
\hline None & 14.3 & 9.5 & \\
\hline$<$ HK\$500 (approx. US\$65) & 34.5 & 42.9 & \\
\hline HK\$500-HK\$1499 (US\$65-US\$193) & 29.8 & 36.9 & \\
\hline HK\$1500-HK\$2499 (US\$193-US\$320) & 13.1 & 6.0 & \\
\hline >HK\$2500 (US\$320) & 8.3 & 4.8 & \\
\hline \multicolumn{4}{|l|}{ Ecological characteristics } \\
\hline \multicolumn{4}{|l|}{ School experience and perspective towards school ${ }^{\mathrm{a}}$} \\
\hline 'Feel good in school' & $2.70(.84)$ & $2.93(.63)$ & $2.035^{*}$ \\
\hline Learn knowledge I will need in the future' & $2.87(.80)$ & $3.15(.57)$ & $2.658 * *$ \\
\hline $\begin{array}{l}\text { 'Academic achievement is very important for my } \\
\text { future' }\end{array}$ & $3.27(.84)$ & $3.47(.55)$ & 1.805 \\
\hline Parental support ${ }^{\mathrm{b}}$ & $3.29(.86)$ & $3.55(.76)$ & $2.095^{*}$ \\
\hline Peer influences ${ }^{c}$ & $3.49(1.32)$ & $3.13(1.12)$ & 1.883 \\
\hline \multicolumn{4}{|l|}{ Psychosocial characteristics } \\
\hline Self-esteem ${ }^{\mathrm{d}}$ & $3.20(.72)$ & $3.49(.60)$ & $2.868 * *$ \\
\hline Attitude towards using drugs ${ }^{\mathrm{e}}$ & $2.18(.67)$ & $1.89(.45)$ & $3.301^{* * *}$ \\
\hline Self-efficacy ${ }^{\mathrm{f}}$ & $3.80(.87)$ & $4.08(.67)$ & $2.287^{*}$ \\
\hline Impulsivity ${ }^{\mathrm{g}}$ & $2.61(.68)$ & $2.53(.56)$ & 0.855 \\
\hline Social desirability ${ }^{\mathrm{h}}$ & $2.21(2.28)$ & $1.48(1.96)$ & $2.18^{*}$ \\
\hline
\end{tabular}

a-point scale: low score indicates negative experience; high score indicates positive school experience.

'5-point scale: low score indicates 'low parental support'; high score indicates 'high parental support'.

'7-point scale: low score indicates 'did not place high importance on friends' opinions and was not negatively affected by peers'; high score indicates 'placed high importance on friends' opinions and negatively affected by peers'.

¿5-point scale: low score indicates low self-esteem'; high score indicates high self-esteem'; note that there were some reverse items.

e 5 -point scale: low score indicates 'low permissiveness towards drug use'; high score indicates high permissiveness towards drug use'; note that there were some reverse items.

f5-point scale: low score indicates low self-efficacy against using drugs'; high score indicates high self-efficacy against using drugs'; note that there were some reverse items.

84-point scale: low score indicates 'high impulsivity'; high score indicates low impulsivity'; note that there were some reverse items.

h8-item yes or no scale: low score indicates low social desirability'; high score indicates 'social desirability'.

$* * * p<.001 ; * * p<.01 ; * p<.05$. 
examine the factors associated with drug-use behaviours or group membership, all of the potential predictors were entered into a stepwise regression model. It is commonly known that the result of multiple regression is affected by the order of entering the variables and the association among the predictors (multi-collinearity). As a remedy, JMP's algorithm automatically switches the order of variables by exploring different combinations. In addition, JMP uses Akaike's information criterion correction (AICc) to indicate the balance between fitness and simplicity of the model. Given all things being equal, the simplest model tends to be the best one (i.e. a better model suggests a smaller AICc), and simplicity is a function of the number of adjustable parameters. AICc instead of R-squared was used because R-squared and adjusted R-squared tend to increase when there are additional variables in the model. In this sense, this approach favours complexity. However, AIC or AICc does not necessarily change by adding variables. Rather, it varies based upon the composition of the predictors, and thus, it is a better indicator of the model quality (Faraway, 2005). After running regression model, data visualization techniques, such as linking and brushing across different distributions, were utilized to further examine the relationship between the significant predictors and drug use. Linking and brushing are interactive visualization techniques. In this process, observations in one distribution are selected (brushing) to examine the position of those observations in another distribution (linking). This technique can be used in a pairwise analysis to verify the association between the dependent and independent variables, and it can also be employed in a multivariate analysis to examine the interaction among multiple variables.

\section{Results}

\section{Participants}

The average age of the participants $(n=172)$ was 15 years. Over $90 \%$ of the present sample self-identified as Chinese. Although they did not reach statistically significant levels, there were more participants in the drug-using than the non-drug-using group living with single parents or friends and receiving higher level of pocket money from family.

$T$-tests revealed three important statistically significant differences between the drug-using group and the control group (Table 1). First, the young people in the drug-using group scored lower than the control group in school experience (e.g. 'feel good in school'; 'learn knowledge I will need in the future'). Second, with regard to parental support, on average, the participants scored 3.29 (standard deviation $(S D)=.86$ ) compared to 3.55 $(S D=.76)$ in the control group, $t<2.095, p<.001$. Third, the secondary students of the drug-using group scored lower self-esteem, lower self-efficacy against using drugs and exhibited higher level of permissive attitude towards drugs than the control group.

Within the drug-using group, five participants reported the first attempt to use drugs was at age 9-11. The common reasons for using drugs were as follows: curiosity, seeking excitement, relieving stress or escapism from negative affect (e.g. harsh reality or boredom). The participants reported that the three most popular locations where they used drugs were 'bar', 'stairs', 'karaoke' followed by 'friends or own home' (Table 2). Only 14 participants (16.3\%) thought that they needed to reduce their consumption, and seven youths indicated that they needed help to deal with their drug-using habits. A total of 74 drug-using participants revealed the types of substance they used. Nine reported daily use (nearly 10\%), 17 reported weekly use (about 20\%) and the remaining $(70 \%)$ reported occasional use or ever use of an illicit drug in the past 6 months (some participants reported occasional use and weekly use at the same time, see Table 3). The three most frequently used substances were organic solvents (e.g. thinners, construction glue), codeine and pills (e.g. Blue Gremlin, Triazolam, R Five). The fact that the total frequency count of types of substance used $(n=104)$ was greater than the number of participants who reported drug-use behaviours $(n=74)$ indicates that some of the participants used more than one substance (Table 3).

\section{Prediction of group membership}

Table 4 presents the results of the logistic regression analysis. The AICc number is 188.735 , which shows that low self-esteem, high social desirability and low impulsivity score (high impulsivity) were significant predictors of drug use. At first glance, this is not fully compatible with the above test of difference results (Table 1), in which impulsivity was not found to be significant by the $t$-test, but multiple logistic regression is a multivariate analysis in which multiple variables are taken into account simultaneously. As shown in Table 4, participants who had lower self-esteem $(b=-1.142$, $p<.01)$ and had higher social desirability $(b=0.208$, $p<.05)$ and impulsivity $(b=0.732, p<.05)$ were more likely to report drug use.

Further data visualization (Figure 1 to 3 ) was conducted to investigate the inter-relationships among the three variables: impulsivity, self-esteem and social desirability, across the participants in drug-using and non-drug-using groups. Using data visualization instead of testing interaction effects based on $p$ values is 
Table 2. Frst experience of using drugs, help-seeking needs and reasons for and locations of taking drugs of the participants $(n=86)$.

\begin{tabular}{|c|c|}
\hline & Number (\%) \\
\hline \multicolumn{2}{|l|}{ First experience of using drugs ${ }^{a}$} \\
\hline 9-11 years old & $5(5.9)$ \\
\hline 12-14 years old & $4(4.7)$ \\
\hline 15-18 years old & $4(4.6)$ \\
\hline \multicolumn{2}{|l|}{ Help-seeking needs } \\
\hline \multicolumn{2}{|l|}{ Do you need to reduce consumption? } \\
\hline No & $20(23.3)$ \\
\hline Yes & 14 (16.3) \\
\hline \multicolumn{2}{|l|}{ Do you need help? } \\
\hline No & $26(30.2)$ \\
\hline Yes & $7(8.1)$ \\
\hline \multicolumn{2}{|c|}{ Reasons for taking drugs (could choose up to 3 reasons) } \\
\hline First: Curiosity & 16 \\
\hline Second: To seek excitement/euphoria & 14 \\
\hline Third: To relieve pressure/stress & 12 \\
\hline To escape from harsh reality & 12 \\
\hline \multicolumn{2}{|l|}{ Others } \\
\hline To relieve boredom & 11 \\
\hline For leisure and recreation & 11 \\
\hline Someone gives me drugs for free & 11 \\
\hline Easy to obtain & 6 \\
\hline To comply with peers' suggestions & 6 \\
\hline Physiological/ psychological addiction & 5 \\
\hline To enhance working/learning ability & 2 \\
\hline \multicolumn{2}{|c|}{ Locations for using drugs (could choose up to 3 locations) } \\
\hline Bar & 43 \\
\hline Stairs & 42 \\
\hline Karaoke & 37 \\
\hline Friends' home & 36 \\
\hline Own home & 36 \\
\hline Park & 25 \\
\hline Internet cafe & 23 \\
\hline School & 11 \\
\hline Car park & 9 \\
\hline Sports court & 6 \\
\hline
\end{tabular}

${ }^{a}$ Only 13 participants (15.1\%) reported their first experience of using drugs.

Table 3. Types of drug used and usage frequency as self-reported by the participants.

\begin{tabular}{|c|c|c|c|}
\hline Type of Substance (could choose more than 1 item) & Occasional use $^{\mathrm{a}}$ & Weekly use $^{\mathrm{a}}$ & Daily use \\
\hline Organic solvent (e.g. thinner, construction glue) & 55 & 12 & 6 \\
\hline Over-dosage of codeine & 13 & 2 & 2 \\
\hline Methamphetamine/ice & 9 & 3 & 2 \\
\hline Tranquilizers (e.g. Blue Gremlin, Triazolam, R Five) & 8 & 2 & 1 \\
\hline Ketamine & 6 & 1 & 1 \\
\hline Ecstasy & 3 & 0 & 0 \\
\hline Cocaine & 2 & 1 & 0 \\
\hline Cannabis/marijuana & 4 & 0 & 0 \\
\hline Heroin & 4 & 1 & 0 \\
\hline Total count & 104 & 22 & 12 \\
\hline Number of participants & 74 & 17 & 9 \\
\hline
\end{tabular}

${ }^{a}$ Some participants reported occasional use and weekly use at the same time. 
Table 4. Regression output based on AICs.

\begin{tabular}{llll}
\hline & Parameter estimate & Chi-square & $p$ value \\
\hline Self-esteem $^{\mathrm{a}}$ & -1.142 & 10.256 & 0.00136 \\
Social desirability $^{\mathrm{b}}$ & 0.208 & 4.061 & 0.04387 \\
Impulsivity $^{\mathrm{c}}$ & 0.732 & 4.784 & 0.02873
\end{tabular}

a5-point scale: low score indicates low self-esteem'; high score indicates 'high self-esteem'; note that there were some reverse items.

b8-item yes or no scale: low score indicates low social desirability'; high score indicates 'high social desirability'.

'4-point scale: low score indicates high impulsivity'; high score indicates low impulsivity'; note that there were some reverse items.

grounded on certain rationales. First, when too many interaction terms are added into the regression model, the model would become highly complicated and the risk of overfitting is higher. Second, visualization, which aims to unveil the patterns of the data at hand, is more in alignment with our research goal. Specifically, the logic of probabilistic inference is concerned with how likely it could obtain the statistics in the long run. However, this approach might fail to detect subtle patterns in a particular sample, which might not be repeatable in the long run (Simon, 2014; Tukey, 1986; Yu, 2014). Thus, pattern recognition rather than probabilistic inferences is more appropriate to tackle and reveal these relationships. Pairwise linking and brushing verifies that lower selfesteem tends to increase drug use, whereas lower social desirability seems to promote a drug-free lifestyle. The high-low split is made around the median, as indicated in the boxplots next to the histograms (see Figures 1 and 2). The scatterplot in Figure 3 suggests that there is a relationship between self-esteem and impulsivity, but this relationship might be obscured by the presence of certain outliers. Nevertheless, a robust regression, which downweighs outliers, verifies the relationship $(p<.0001)$. In other words, youths who are low in self-esteem are more likely to be impulsive (low impulsivity scores) or deficient in planning, a related construct. Figure 4 reveals that youths who have both low self-esteem and low impulsivity scores (rather impulsive) tend to use drugs.

\section{Discussion}

This study attempted to adopt an ecological perspective to study student drug use in Hong Kong using a casecontrolled methodology. Correlates of drug use across micro to macro were examined, and at the end, only three individual-level variables, namely, self-esteem, social desirability and impulsivity, were found to have statistically significant differential weights to predict drug-use and non-drug-use behaviour.

Self-esteem and drug use have been studied for decades (e.g. McGee \& Williams, 2000; McKay, Sumnall, Cole, \& Percy, 2012; Newcomb, Maddahian, \&
Bentler, 1986). The findings suggest there is a robust association between low self-esteem and drug use, whereas a recent study by Marshall et al. (2015) revealed that high self-compassion (defined as accepting selfdoubt and adversity as part of life) worked as a buffer to protect the adolescents who were low in self-esteem from poor mental health, including addiction problems. Social desirability is both an individual difference variable and a response bias of wanting to 'obtain approval by responding in a culturally appropriate and acceptable manner' (Crowne \& Marlowe, 1960, p. 350; Davis, Doherty, \& Moser, 2014; Richman, Kiesler, Weisband, \& Drasgow, 1999; Zemore, 2012). Within drug use studies, high social desirability is often found to be related to lower self-reported use of drug use or alcohol, and it could either strengthen or upset adherence to intervention depending on whether the client regards treatment adherence as socially desirable. Inconsistent with the majority of studies, the present finding shows that the participants who had high self-esteem and but were low in tendency to seek social approval were likely to be the non-drug users. The role of impulsivity in drug use is less straight-forward and more complicated. Although there is a strong association between self-esteem and impulsivity, in a pairwise context, impulsivity does not seem to be a crucial predictor of drug use. However, when the youths are low in both self-esteem and impulsivity scores (being impulsive), the risk of drug use substantially increases.

The present study is one of the few investigations in Hong Kong that has found that those young people attending predominantly Chinese speaking secondary schools who use drugs are from diverse cultural backgrounds. In the present study, 8 of the 86 drug-using participants (9.3\%) identified themselves as non-Chinese; 19 participants (22.4\%) in the drug-using group were not born in Hong Kong. Their average number of years in the territory was 6.5 years. Nevertheless, this study cannot draw definitive conclusion on whether ethnic minority young people are at greater risk in developing druguse problem compared with their counterparts in the context of Hong Kong due to the small number of individuals included in this analysis. In addition, the findings showed that the participants frequently used organic solvents (e.g. thinners, construction glue), codeine and pills (e.g. Blue Gremlin, Triazolam, R Five), which deviated from the findings of the Narcotics Division, 2013, that the three most common drugs for secondary students were cannabis, ketamine and ice in 2011/2012 (Narcotics Division of the Security Bureau, Hong Kong Special Administrative Region, 2014). The differences may be explained by the fact that Narcotics data were collected from general members of the public who were known to government drug and addiction services, whereas the present study reached only the secondary school students and they had not sought help from addiction services. 


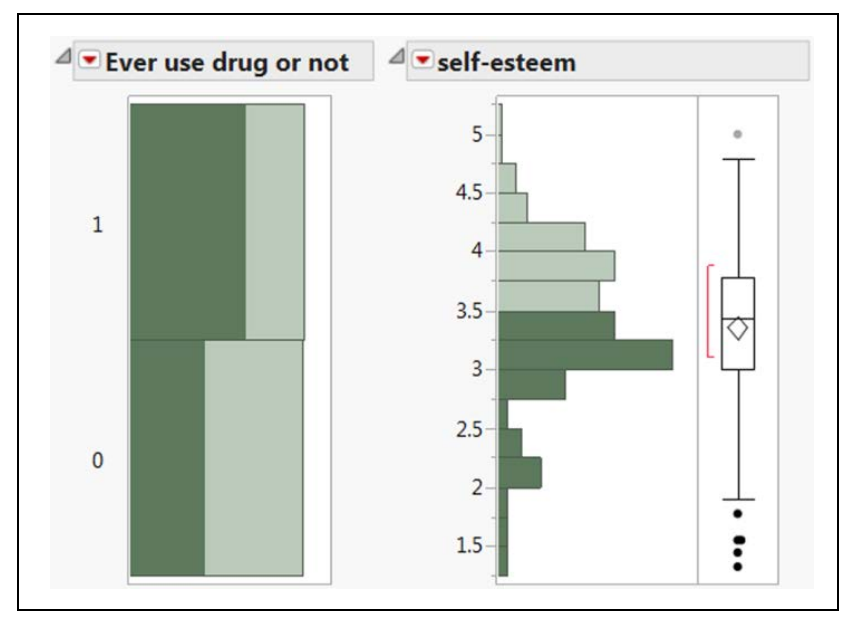

Figure 1. Brushing and linking of two distributions indicates that youths with low self-esteem tend to be drug users. The darker shade represents the participants reported lower selfesteem (based on the median split), while the lighter shade represents the participants reported higher self-esteem.

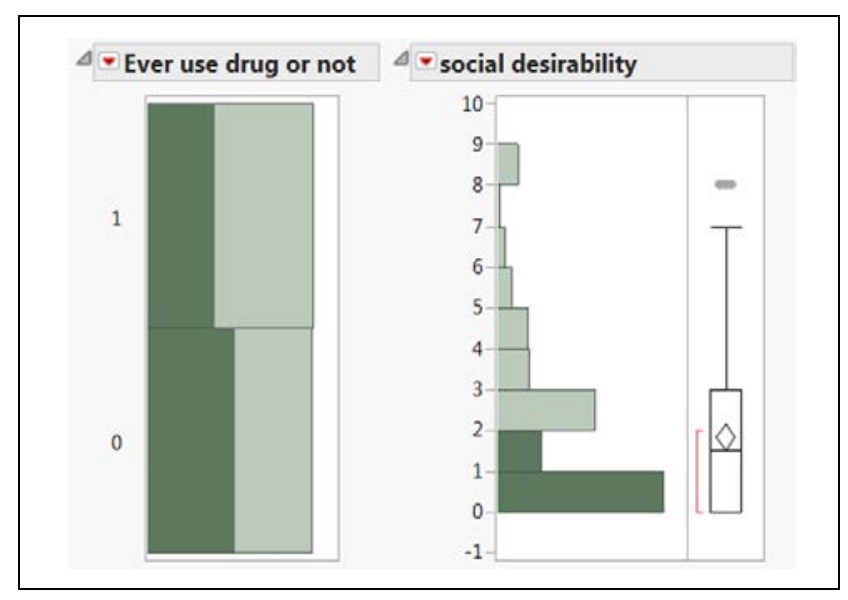

Figure 2. Brushing and linking of two distributions indicates that low social desirability youths tend to be drug free. The darker shade represents the participants who have low socia desirability, while the lighter shade represents the participants reported higher desirability.

In terms of the implications that can be drawn from the present study, EST advocates that preventive efforts and interventions should not merely focus on prohibition (Vimpani, 2005). Instead, they should address each of the relevant systems and their interplay (Randall \& Cunningham, 2003). Based on the present findings, the following interventions are recommended: (1) Individuallevel interventions to address young people's self-esteem and to strengthen their ability to plan and reduce the level of impulsivity. It is important to see young people as part of the solution, not the source of the problem; (2) Familylevel interventions to enhance parents' or carers' ability to foster positive youth development such as selfconfidence, positive evaluation of oneself and

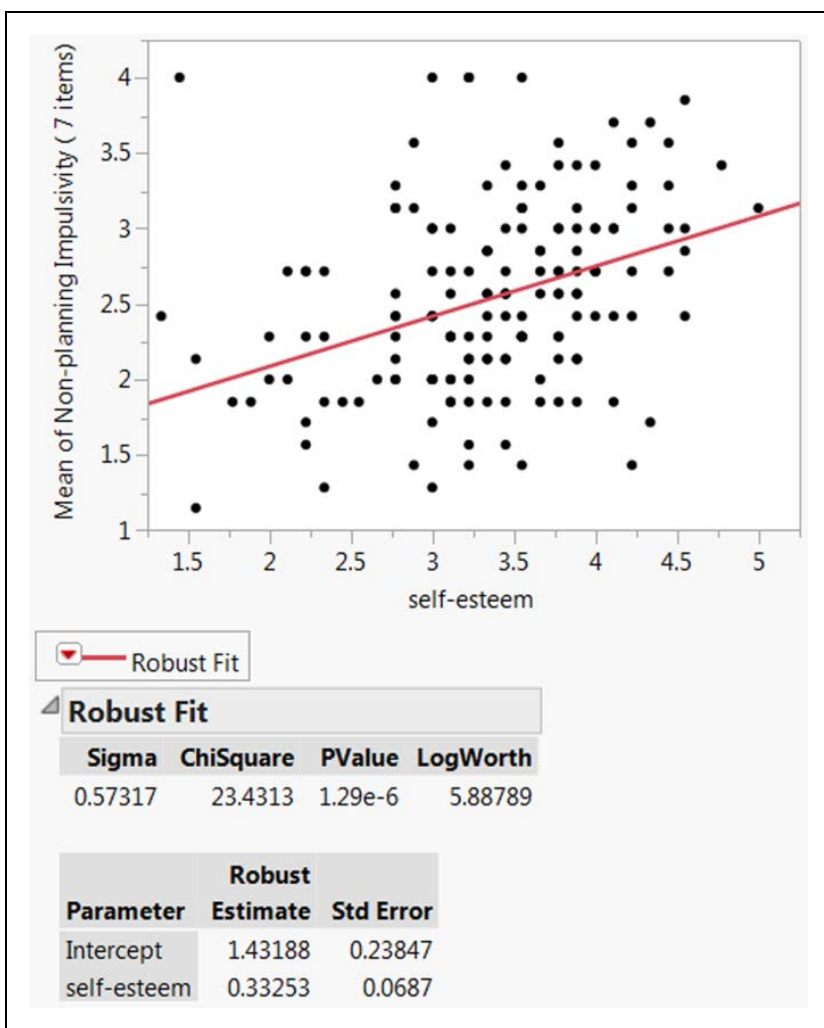

Figure 3. The robust regression fit, which down-weight outliers, indicates that there is a strong relationship between self-esteem and impulsivity.

assertiveness; (3) School-level interventions to enrich young people's experiences at school and to ensure that young people are introduced to a curriculum that is highly relevant to their future (either entering the workforce or participating in further studies); (4) Community- or societal-level interventions to provide extra support and resources (e.g. working across social and health services sectors) for young people who are newly arrived migrants in the host community (Tse, Yu, Rossen, \& Wang, 2010).

The current study has three limitations. Although the sample size of the wider study was large, the number of individuals included in the present case-control analysis was small. Second, the present sample may not represent the more severe clinical cases of young people who are heavy drug users. For instance, the participants in the present study were recruited from the school system, and they had to have sufficient concentration to complete the survey. Third, the analysis was based on self-reported information of drug-use behaviours and some participants might not report their drug use due to perceived social desirability. To conclude, the logistic regression model and the data visualization found that the three variables which were linked to non-drug-using status were as follows: self-esteem, social desirability and impulsivity. 


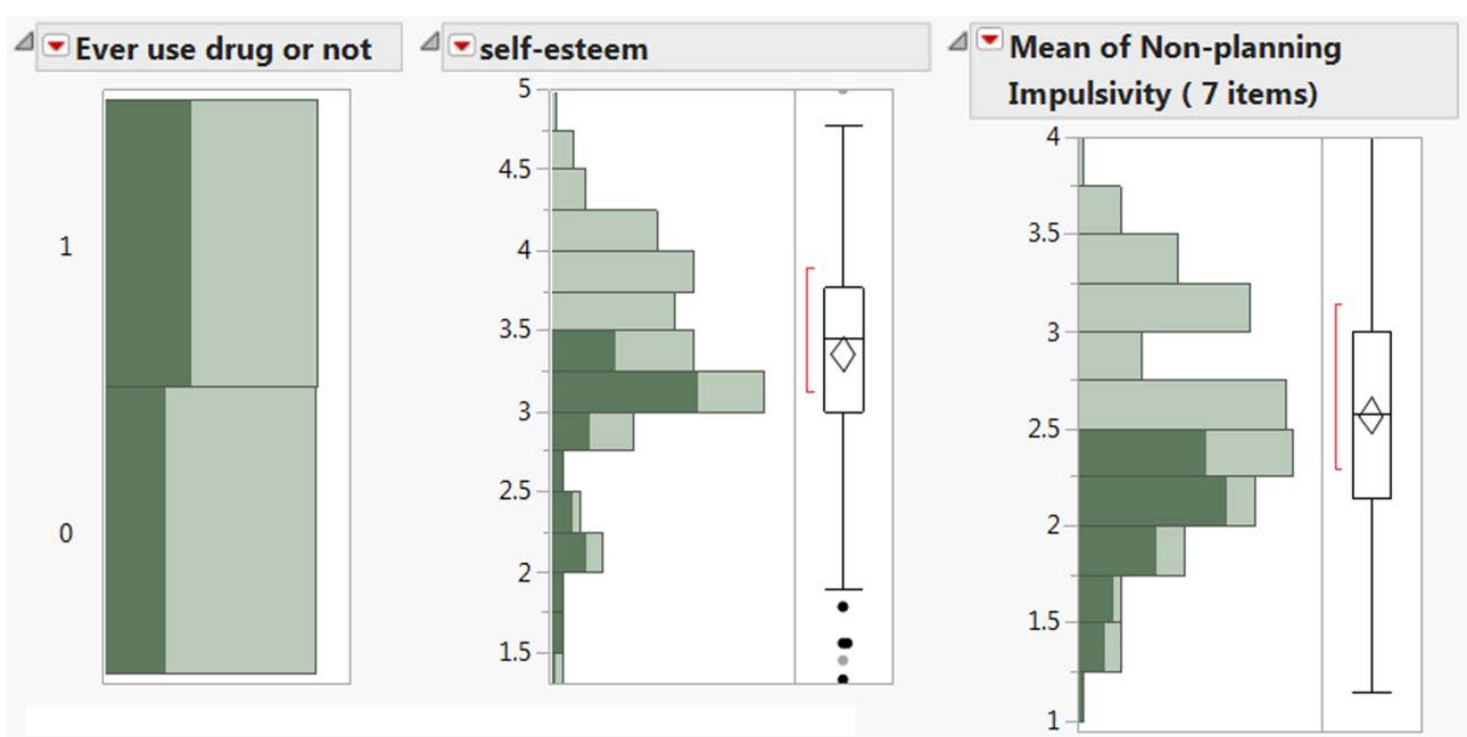

Figure 4. Brushing and linking of three distributions indicates that youths who have both low self-esteem and low scores in impulsivity (rather impulsive and lack of planning) tend to use drug. The darker shade represents the participant whose are impulsive and lack of planning (based on the median split), while the lighter shade represents the participants whose are less impulsive.

Therefore, it is recommended that parents, teachers and mental health professionals should deploy resources to these individual-level, attitudinal factors. Furthermore, from the findings in terms of ecological factors, providing more parental support and engaging the young people in school activities are important in drug-use prevention.

\section{Conflict of interest}

The authors declare that there is no conflict of interest.

\section{Funding}

This study was funded by the Joint Committee for Community Programme against Youth Drug Abuse, Hong Kong.

\section{Note}

1. Starting from school year 2009-2010, Form 7 has been eliminated; universities provide four years of education instead of three.

\section{References}

Barlow, J. (2010). Substance misuse: The implications of research, policy and practice. London, England: Jessica Kingsley Publishers.

Barnabas Charitable Service Association Limited. (2009). Survey report on the drug-taking attitude of senior primary school students. Hong Kong: Author.
Bronfenbrenner, U. (1986). Ecology of the family as a context for human development: Research perspectives. Developmental Psychology, 22, 723-742.

Crowne, D. P., \& Marlowe, D. (1960). A new scale of social desirability independent of psychopathology. Journal of Consulting Psychology, 24, 349-354.

Davis, C. G., Doherty, S., \& Moser, A. E. (2014). Social desirability and change following substance abuse treatment in male offenders. Psychology of Addictive Behaviors, 28, 872-879.

DeVires, H., Dijkstra, M., \& Kuhlman, P. (1988). Self-efficacy: The third factor besides attitude and subjective norm as a predictor of behavioural intentions. Health Education Research, 3, 273-282.

Faraway, J. (2005). Extending the linear model with $R$ : Generalized linear, mixed effects and nonparametric regression models. London, England: Chapman \& Hall.

Fuligni, A. J., \& Eccles, J. S. (1993). Perceived parent-child relationships and early adolescents' orientation toward peers. Developmental Psychology, 29, 622-632.

Gossop, M. (2007). Living with drugs. Hampshire, UK: Ashgate.

Hong, J. S., Huang, H., Sabri, B., \& Kim, J. S. (2011). Substance abuse among Asian American youth: An ecological review of the literature. Children and Youth Services Review, 33, 669-677. doi:10.1016/j.childyouth. 2010.11.015 
The Hong Kong Federation of Youth Groups. (2008, April 18). HKFYG youth study series tackling drug abuse by young people: A study on preventive education and publicity strategies. Youth Matters, Issue 124.Retrieved from https://m21.hk/partnership/issue124_apr2008/news_long.ht $\mathrm{ml}$

Jessor, R., Van Den Bos, J., Vanderryn, J., Costa, F. M., \& Turbin, M. S. (1995). Protective factors in adolescent problem behavior: Moderator effects and developmental change. Developmental Psychology, 31, 923-933.

Knyazev, G. G. (2010). Reward seeking as a predictor of drug use in youth: Effect of gender and social environment. Open Addiction Journal, 3, 1-8.

Kuo, C.-H., Lin, H.-S., \& Li, P.-Y. (2012). Using ecological systems theory in community health assessment. Journal of Nursing, 59, 99-105.

Lee, S., \& Lee, A. M. (2000). Disordered eating in three communities of China: A comparative study of female high school students in Hong Kong, Shenzhen, and rural Hunan. International Journal of Eating Disorders, 27, 317-327.

Marshall, S. L., Parker, P. D., Ciarrochi, J., Sahdra, B., Jackson, C. J., \& Heaven, P. C. (2015). Self-compassion protects against the negative effects of low self-esteem: A longitudinal study in a large adolescent sample. Personality and Individual Differences, 74, 116-121.

McGee, R. O. B., \& Williams, S. (2000). Does low self-esteem predict health compromising behaviours among adolescents? Journal of Adolescence, 23, 569-582.

McKay, M. T., Sumnall, H. R., Cole, J. C., \& Percy, A. (2012). Self-esteem and self-efficacy: Associations with alcohol consumption in a sample of adolescents in Northern Ireland. Drugs: Education, Prevention and Policy, 19, 72-80.

Narcotics Division of the Security Bureau, Hong Kong Special Administrative Region. (2010). The 2008/09 survey of drug use among students. Retrieved from http://www.nd.gov.hk/pdf/survey_drug_use/20082009/Report.pdf

Narcotics Division of the Security Bureau, Hong Kong Special Administrative Region. (2014). Central registry of drug abuse (Sixty-third report). Retrieved from http://www.nd.gov.hk/pdf/report/crda_63rd/crda_63rd_full_ report.pdf

National Institute on Drug Abuse. (2013). Monitoring the future survey. Retrieved from http://www.drugabuse.gov/ monitoring-future-survey-overview-findings-2013

Newcomb, M. D., Maddahian, E., \& Bentler, P. M. (1986). Risk factors for drug use among adolescents: Concurrent and longitudinal analyses. American Journal of Public Health, 76, 525-531.
Nunnally, J. C. (1978). Psychometric theory (2nd ed.). New York, NY: McGraw-Hill.

Patton, J. H., Stanford, M. S., \& Barratt, E. S. (1995). Factor structure of the Barratt impulsiveness scale. Journal of Clinical Psychology, 51(6), 768-774.

Randall, J., \& Cunningham, P. (2003). Multisystemic therapy: A treatment for violent substance-abusing and substancedependent juvenile offenders. Addictive Behaviour, 28, 1731-1739.

Richman, W. L., Kiesler, S., Weisband, S., \& Drasgow, F. (1999). A meta-analytic study of social desirability distortion in computer-administered questionnaires, traditional questionnaires, and interviews. Journal of Applied Psychology, 84, 754-775.

SAS Institute. (2013). JMP [Computer Software]. Cary, NC: Author.

Shek, D. T. L. (1997). The relation of family functioning to adolescent psychological well-being, school adjustment, and problem behavior. Journal of Genetic Psychology, 158, 467-479.

Simon, P. (2014). The visual organization: Data visualization, big data, and the quest for better decisions. Hoboken, NJ: John Wiley.

Stormshak, E., \& Dishion, T. (2009). A school-based, familycentered intervention to prevention substance use: The family check-up. American Journal of Drug and Alcohol Abuse, 35, 227-232.

Tse, S., Yu, A. C., Rossen, F., \& Wang, C. W. (2010). Examination of Chinese gambling problems through a socio-historical-cultural perspective. The Scientific World Journal, 10, 1694-1704.

Tukey, J. W. (1986). The collected works of John W. Tukey, Vol. IV: Philosophy and principles of data analysis (19651986) (L. V. Jones, Ed.). Pacific Grove, CA: Wadsworth.

Vimpani, G. (2005). Getting the mix right: Family, community and social policy interventions to improve outcomes for young people at risk of substance misuse. Drug and Alcohol Review, 24, 111-125.

Wheeler, S. B. (2010). Effects of self-esteem and academic performance on adolescent decision-making: An examination of early sexual intercourse and illegal substance use. Journal of Adolescent Health, 47, 582-590.

Wills, T. A., Vaccaro, D., \& McNamara, G. (1992). The role of life events, family support, and competence in adolescent substance use: Test of vulnerability and protective factors. American Journal of Community Psychology, 20, 349-374.

Yu, C. H. (2014). Dancing with the data: The art and science of data visualization. Saarbrucken, Germany: Lambert Academic Publishing.

Zemore, S. E. (2012). The effect of social desirability on reported motivation, substance use severity, and treatment attendance. Journal of Substance Abuse Treatment, 42, 400-412. 